\title{
DIELECTRIC PROPERTIES OF ICE AND SNOW-A REVIEW
}

\author{
By S. Evans
}

(Scott Polar Research Institute, Cambridge, England)

\begin{abstract}
The permittivity and loss tangent of naturally occurring ice and snow are considered. The direct-current conductivity is considered only when it is of importance to the alternating-current and radiofrequency properties. Laboratory measurements on pure ice, and deliberately contaminated ice, are included to help in explaining and extrapolating the behaviour of natural ice and snow. The lower band of frequencies from Io c./sec. to I Mc./sec. is occupied by a relaxation spectrum in which the relative permittivity falls from approximately $\mathrm{I}$ oo to 3 . The loss tangent reaches a maximum at a frequency which varies from $50 \mathrm{c}$. / sec. to $50 \mathrm{kc}$. $/ \mathrm{sec}$. as the temperature increases from $-60^{\circ} \mathrm{C}$. to $0^{\circ} \mathrm{C}$. We are interested in the effect of snow density, impurities, stress, crystal size, and orientation. For frequencies much greater than I Mc./sec., the relative permittivity is $3.17 \pm 0.07$. The loss tangent reaches a minimum value at approximately $\mathrm{I}, \mathrm{Ooo} \mathrm{Mc}$. $/ \mathrm{sec}$. beyond which the dominant influence is infra-red absorption. The minimum is $10^{-3}$ at $0^{\circ} \mathrm{C}$. or $2 \times 10^{-5}$ at $-60^{\circ} \mathrm{C}$. These values are greatly increased by impurities or free water. Some possible applications to glaciological field measurements are mentioned.
\end{abstract}

RÉsumé. Revue des propriétés diélectriques de la glace et la neige. La permitivité et le facteur de perte de la glace et de la neige naturellement rencontrées sont discutés. La conductivité en courant continu est seulement considérée dans la mesure où elle est importante pour les propriétés des courants alternatifs et des fréquences radio. Des mesures de laboratoire sur de la glace pure, ou artificiellement impure, sont ajoutées pour aider l'explication et l'extrapolation du comportement de la glace et de la neige naturelle. La basse bande de fréquences de $10 \mathrm{~Hz}$ à I $\mathrm{MHz}$ est occupée par un spectre de relaxation où la permitivité relative tombe de 100 à 3 . Le facteur de perte atteint un maximum pour une fréquence qui varie de $50 \mathrm{~Hz}$ à $50 \mathrm{kHz}$ lorsque la température croit de $-60^{\circ} \mathrm{C}$ à $0^{\circ} \mathrm{C}$. Nous sommes intéressés par l'effet de la densité de la neige, des impuretés, des contraintes, des dimensions des cristaux et de leur orientation. Pour les fréquences supérieures à $\mathrm{I} \mathrm{MHz}$, la permitivité relative est de $3,17 \neq 0,07$. Le facteur de perte atteint un minimum pour environ $1000 \mathrm{MHz}$ au-delà de laquelle l'influence dominante est une absorption infra-rouge. Le minimum est $10^{-3}$ à $0^{\circ} \mathrm{C}$ ou $2.10^{-5}$ à $-60^{\circ} \mathrm{C}$. Ces valeurs sont considérablement augmentées par des impuretés ou de l'eau libre. Quelques applications possibles à la glaciologie sont mentionnées.

Zusammenfassung. Dielektrische Eigenschaften von Eis und Schnee-eine Übersicht. Die Durchlässigkeit und die Schwundgrenze von natürlichem Eis und Schnee werden untersucht. Die Gleichstrom-Konduktivität wird nur dann in Betracht gezogen, wenn sie für das Verhalten des Wechselstromes und der Radio-Frequenzen von Bedeutung ist. Zur Deutung und Extrapolation des Verhaltens von natürlichem Eis und Schnee werden Labormessungen an reinem Eis und künstlich verschmutztem Eis herangezogen. Der niedrige Frequenzbereich von $10 \mathrm{~Hz}$ bis $1 \mathrm{MHz}$ wird von einem Relaxationsspektrum eingenommen, in dem die relative Durchlässigkeit von ca. Ioo auf 3 abfällt. Die Schwundgrenze erreicht ein Maximum bei einer Frequenz, die von $50 \mathrm{~Hz}$ bis $50 \mathrm{KHz}$ wechselt, wenn die Temperatur von $-60^{\circ} \mathrm{C}$ auf $0^{\circ} \mathrm{C}$ ansteigt. Weiter interessiert der Einfluss der Dichte, der Verunreinigungen, der Spannung, der Kristallgrösse und -orientierung. Für Frequenzen über I $\mathrm{MHz}$ beträgt die relative Durchlässigkeit $3,17 \pm 0,07$. Die Schwundgrenze erreicht ein Minimum bei ca. $1000 \mathrm{MHz}$; jenseits davon ist die Infrarot-Absorption der dominierende Einfluss. Das Minimum beträgt $\mathrm{IO}^{-3}$ bei $\mathrm{o}^{\circ} \mathrm{C}$ oder $2 . \mathrm{IO}^{-5}$ bei $-60^{\circ} \mathrm{C}$. Diese Werte werden durch Verunreinigungen oder freies Wasser beträchtlich erhöht. Einige Anwendungsmöglichkeiten für glaziologische Feldmessungen werden erwähnt.

\section{INTRODUCTION}

It is possible that in the near future the electrical properties of snow and ice may find various applications to glaciological problems in the field. Using established geophysical prospecting techniques, direct-current electrical resistivity measurements have already been used on polar and temperate glaciers to obtain some information about the depth of snow, and underlying rock type. This paper is concerned with alternating-current and radiofrequency properties of ice and snow. The information available in the literature has been collected with the intention of finding the gaps in present knowledge, and new experimental work directed to filling the gaps which appear to be of interest will appear in a later paper. Applications of the electrical properties to the measurement of ice thickness, temperature, mechanical stress, and crystal orientation, are indicated in this paper and it is hoped that further ideas will be stimulated. A complete annotated bibliography of published measurements is given in chronological order in Appendix A. In the text, references to other authorities have been kept to a minimum. 


\section{The Relaxation Spectrum}

\section{I.I Pure ice}

Many workers have investigated the large dielectric dispersion which occurs in ice at audio- and low radio-frequencies and it is therefore not our intention to treat this range or its relation to the molecular structure of ice in detail.

In general, measurements of various authors are in good agreement with one another and with the Debye equation for dielectrics consisting of polar molecules having a single relaxation time. This is a common type of spectrum and some of the important properties are given in Appendix B; the unusual features of ice are its extremely high static permittivity (of the order of 100 ) and its long relaxation time (of the order of $\mathrm{IO}^{-4} \mathrm{sec}$.). In comparing the various measurements there are a number of variables to be considered. Temperature is important because the relaxation time of all materials is increased as the temperature is reduced, the possible effect of impurities must be considered, and it is believed that mechanical stress may have an influence. If the medium considered is snow, then density is important because it is a mixture of two dielectrics, ice and air, and this introduces at least one further variable which characterizes the shape and orientation of the particles comprising the mixture.

Restricting ourselves to pure ice, free from cracks, bubbles, impurities, and stress, a representative Cole-Cole diagram at $-I^{\circ} \mathrm{C}$. is shown by curve (a) in Figure $\mathrm{I}$. The relaxation time, $\tau$, can be related to absolute temperature, $T$, by the Boltzmann condition which gives

$$
\tau=\tau_{0} \exp (E / R T)
$$

and Auty and Cole (1952) obtained values of $\tau_{\text {o }}$ (the time constant) and $E$ (the energy) for dipole orientation. When their values are substituted in (I) we obtain

$$
\log _{\mathrm{I} 0} \tau=2900 / T-\mathrm{I} 5 \cdot 3
$$

and this relation has been used to plot the solid line in Figure 2 assuming the values of $\tau_{0}$ and $E$ to be substantially independent of temperature.

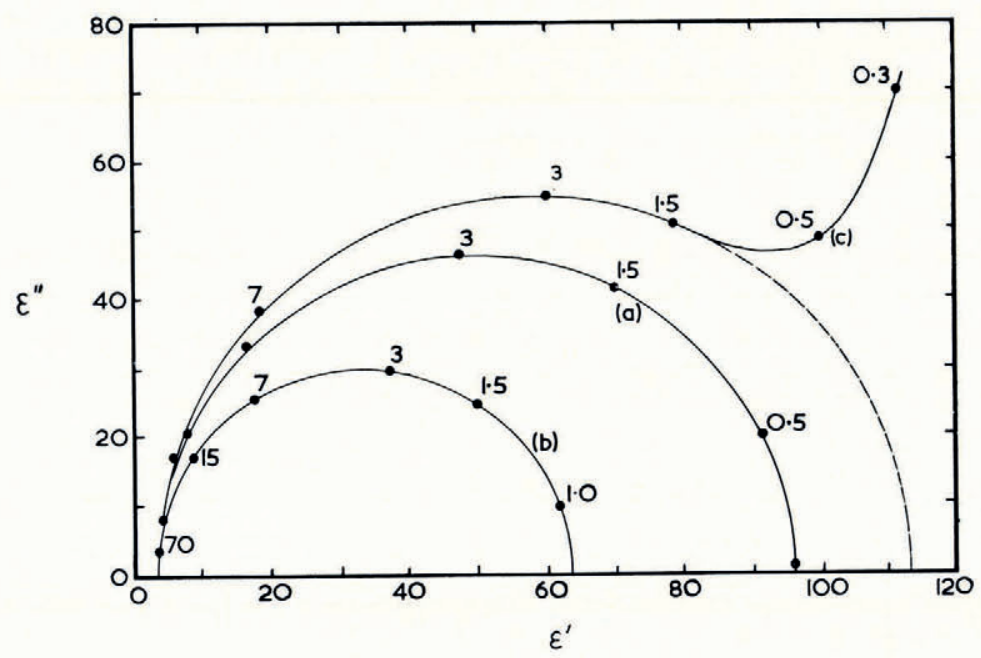

Fig. 1. Relative permittivity (abscissae) and loss factor (ordinates) of ice samples at $-10 \cdot 8^{\circ} \mathrm{C} .($ after Auty and Cole, I952). Frequencies in kilocycles per second are marked against measured points (a) pure ice, free from cracks, bubbles, impurities, or stress; $(b)$ with a crack perpendicular to the electric field reducing $\epsilon_{s} ;(c)$ with impurities, increasing the d.c. conductivity and increasing $\epsilon_{s}$ 


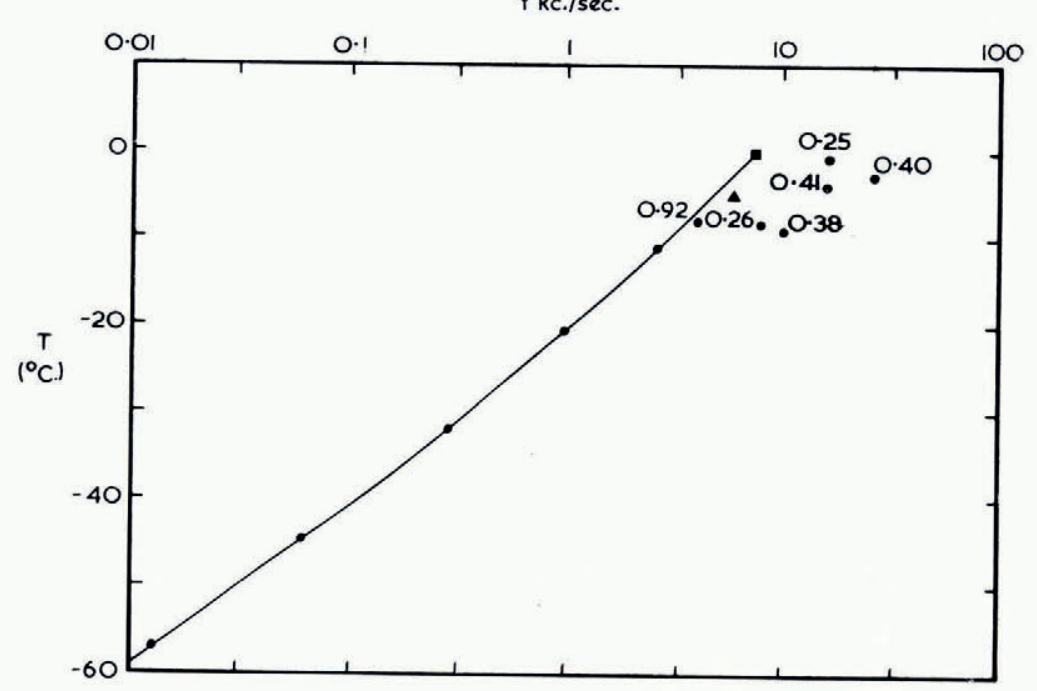

Fig. 2. Frequency for which the loss factor, $\epsilon^{\prime \prime}$, is a maximum (abscissae) plotted logarithmically versus temperature (ordinates). The measurements of Auty and Cole (1952) are marked on the solid line which is computed from equation (2). $\mathbf{\Delta}$ Laboratory measurements on pure ice by Lamb (1946); - Field measurements on Athabaska Glacier by Watt and Maxwell (196o); - Natural snow samples from Sapporo City measured in the laboratory by Kuroiwa [ ${ }^{2956}$ ]. The density in $\mathrm{g} . / \mathrm{cm} .{ }^{3}$ is given alongside each point

The limiting value of permittivity at high frequency is found to be independent of temperature and equal to $3 \cdot I_{5} \pm 0.05$ but there is an increase in the low frequency or static value, from 92 to $\mathrm{IO}_{3}$, in polycrystalline ice as the temperature is reduced from $0^{\circ} \mathrm{C}$. to $-45^{\circ} \mathrm{C}$. and a steeper rise thereafter. Powles (I 952) has derived theoretical values for the static permittivity by considering a finite number of oxygen atoms in specific tetrahedral structures. He is able to include up to 24 atoms in an aggregate and to calculate the electric effect, and hence the contribution to the total polarization, of a single atom near the centre. Beyond 24 atoms the calculations become too long and the effect on the result small. The average dipole moment is then used in Fröhlich's formula for the permittivity of a solid. Two results of Powles, on the assumption that all configurations of the aggregate are equally probable, and the alternative assumption that the probability is related to the electrostatic energy of the system, are shown in Figure 3 together with some experimental values. Careful measurements on individual crystals show that there is appreciable anisotropy. This was ignored, for simplicity, in Powles' model but it may provide a means of examining the degree of crystal orientation by measuring the static permittivity in naturally occurring ice masses.

\section{I.2 Snow}

The behaviour of a mixture of dielectrics has been discussed by a number of authors who generally consider a sparse distribution of separate particles, of idealized mathematical shape, within a second dielectric medium (Wagner, I913; Sillars, 1937; Vieweg and Gast, I943). However Weiner ( I9 Io) showed empirically that even in a dense distribution a single parameter, which he called the Formzahl, is often sufficient to describe how one medium is dispersed within the other. Basically this amounts to assuming that the geometry of the electric field is not a function of the relative proportion of the two media and this cannot be strictly true. It is easy to see that if the particles of the high-permittivity medium are elongated in the direction 


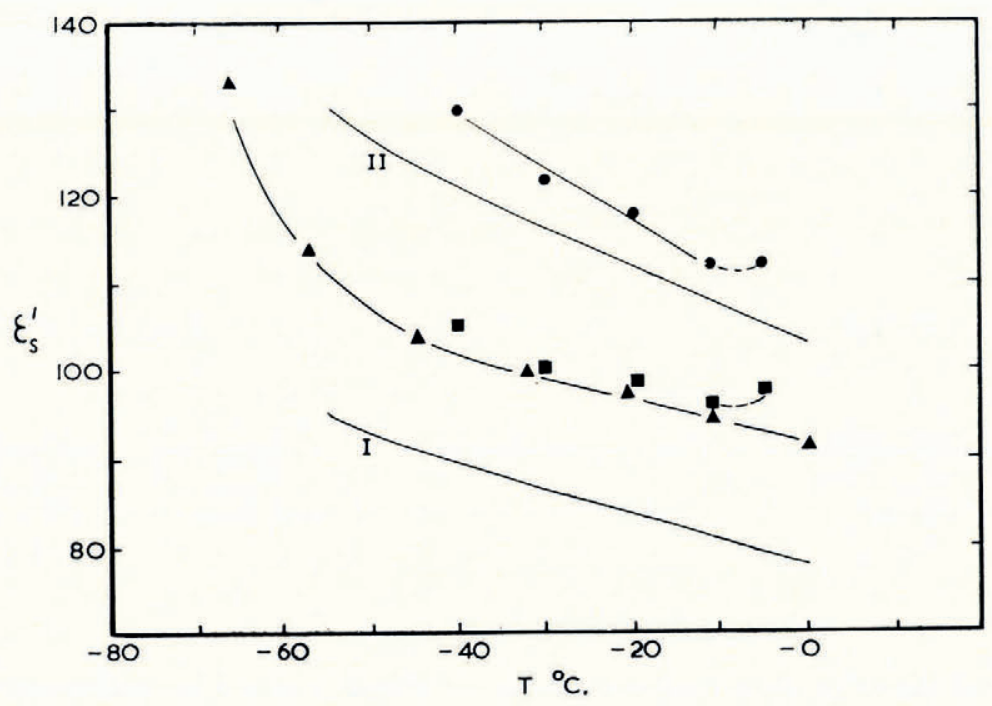

Fig. 3. Permittivity of ice at low frequencies (ordinates) against temperature in degrees centigrade (abscissae). $\mathbf{\Delta}$ Polycrystalline sample (Auty and Cole, I952); Single crystal, electric field parallel to c-axis; $\mathbf{\square}$ Single crystal, electric field perpendicular to c-axis; no pure real value at $-5^{\circ} \mathrm{C}$. (Humbel and others, 1953). I and II: limiting cases from Powles' (1952) calculation

of the electric field, the combined permittivity will be higher than if they lie across the field and the mixture may be anisotropic, requiring different Formzahl in different directions. A mixture of long thin particles, randomly orientated, will be isotropic in the mass but have a higher permittivity than a suspension of spherical particles having the same volume ratio. Some illustrative examples are given in Figure 4, and in Figure I curve (b) shows the effect of an air crack perpendicular to the electric field direction in an otherwise solid block of ice.

Weiner found that if $\epsilon_{m}, \epsilon_{\mathrm{I}}$ and $\epsilon_{2}$ are the relative permittivities of the mixture and the two separate media respectively then

$$
\frac{\epsilon_{m}-\mathrm{I}}{\epsilon_{m}+u}=p\left(\frac{\epsilon_{1}-\mathrm{I}}{\epsilon_{\mathrm{I}}+u}\right)+(\mathrm{I}-p)\left(\frac{\epsilon_{2}-\mathrm{I}}{\epsilon_{2}+u}\right)
$$

where $p$ is the proportion of the total volume occupied by medium I and $u$ is the Formzahl. The formula includes the effect of losses if complex values are substituted for $\epsilon_{\mathrm{I}}$ and $\epsilon_{2}$, but if the losses are such that $\tan ^{2} \delta \ll \mathrm{I}$ then only the real parts need to be substituted in equation (3) to find the real part of $\epsilon_{m}$, and in this section we restrict the application of the formula to the limiting values of permittivity at low and high frequencies, $\epsilon_{s}$ and $\epsilon_{\infty}$ respectively. Furthermore, in the case of snow, medium 2 is air, $\epsilon_{2}=\mathrm{I}+j \mathrm{j}$, and the second term on the right hand side of equation (3) is zero. Medium $\mathrm{I}$ is ice and thus $p=\rho / 0 \cdot 9^{2}$ where $\rho$ is the specific gravity of the snow.

In Figure 4 independent measurements are compared with relationships computed from Weiner's formula. Cumming's results correspond to a Formzahl value between 2 and 4 whilst for Kuroiwa's results a value greater than io is required. Cumming's snow samples came from Ottawa, Canada, and Kuroiwa's from Sapporo city, Japan, so that it would not be surprising if there had been more opportunity for bonds to form between the ice crystals by partial thawing and refreezing in Kuroiwa's samples. They included new snow, compact snow, and granulated snow and he found in a separate investigation that the Formzahl value, $u$, increased with time. It is suggested that any values of $u$ between 2 and infinity must be 

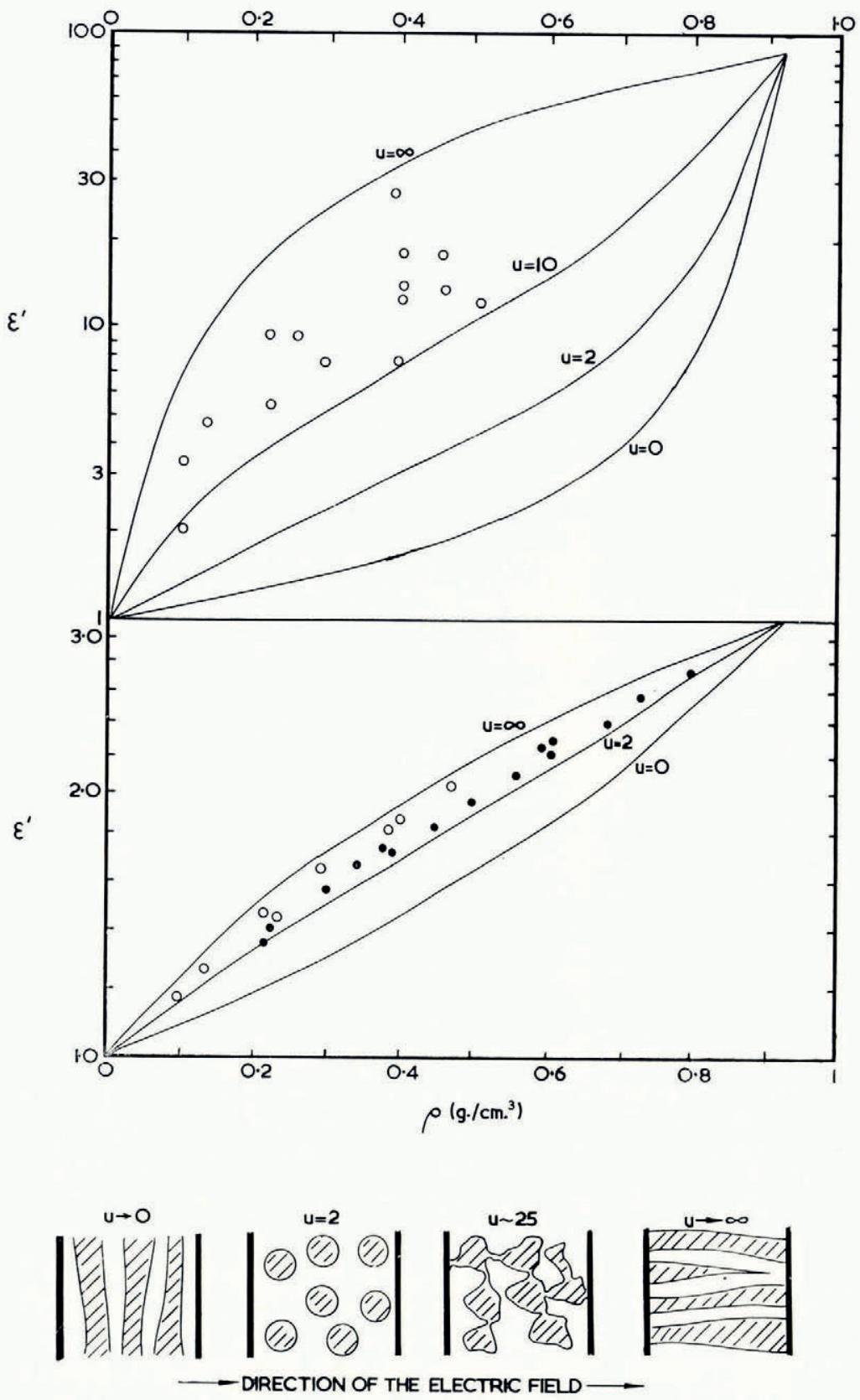

Fig. 4. Relative permittivity of snow (ordinates) versus density (abscissae). The upper curves are computed as explained in section 1.2 for snow particles having the characteristic Formzahl values $u=0,2,10$, and $\infty$ in Weiner's formula and taking the relative permittivity of solid ice to be 90 at low frequencies. The lower curves are for the limiting value of the permittivity at high frequencies, taken to be 3.2 for solid ice. Measured values: 0 due to Kuroiwa [1956] at frequencies less than I kc./sec. and at $3 \mathrm{Mc}$. $/ \mathrm{sec}$., due to Cumming $\left(195^{2}\right)$ at $9,375 \mathrm{Mc}$. $/ \mathrm{sec}$. The sketches beneath the graphs show how snow structure is related to the Formzahl 
expected in practice according to the structure of the snow; the curves for these two values set some limit to the permittivity of snow of known specific gravity.

There is no obvious way in which the relaxation time should be related to snow density but the available measurements on snow of known specific gravity (due to Kuroiwa) all have shorter relaxation times than pure ice. In Figure 2 the experimental results are compared with a curve derived from the relaxation time of pure ice given by equation (2). G. de Q. Robin has suggested (private communication) that this relationship might be a basis for the measurement of temperature within large bodies of snow, and the method looks promising because the variation of frequency is so large. It will be necessary to establish that there are no important variables other than the temperature; Gränicher and others (1957) and Brill (1957) find that impurities in solid solution shorten the relaxation time and Westphal (private communication) finds that mechanical stress shortens the relaxation time. It would clearly be worth while to obtain measurements at lower temperatures on naturally occurring snow of known density and conductivity, and if possible, where some estimate of the stress can be made.

\section{I.3 Effect of impurities and liquid water}

The presence of impurities in small quantities, or of water when the temperature is near freezing point, may have two effects. First there is the effect on the permittivity due to the mixture of dielectric media as discussed above, and this is especially important if liquid water is present because the relative permittivity of water remains very high up to frequencies in the centimetre wavelength band. Values of permittivity at high frequency for a mixture of snow of specific gravity 0.5 (for which we take the real part of the permittivity at high frequency $\left.\epsilon^{\prime}=2\right)$ and liquid water $\left(\epsilon^{\prime}=80\right)$ have been calculated for various values of the Formzahl and the results are compared in Figure 5 with some measurements on wet snow of the same

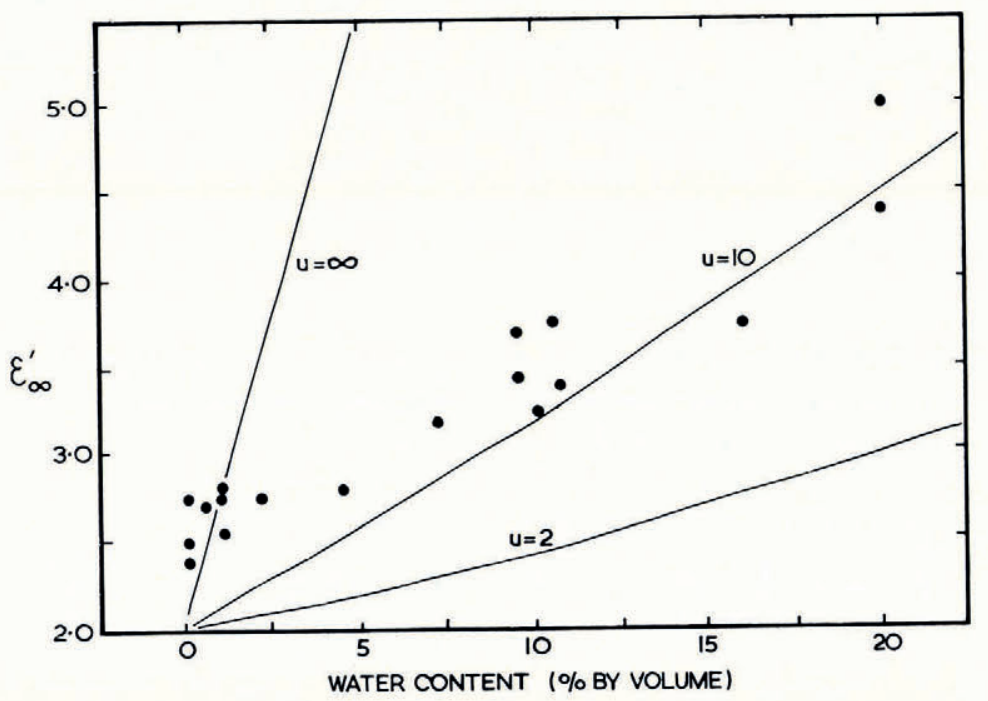

Fig. 5. Permittivity of wet snow at high frequencies (ordinates) versus volume percentage of liquid water (abscissae). The permittivity of the dry snow is assumed to be $2 \cdot 0$, corresponding to a specific gravity of approximately $0 \cdot 5$. The continuous permitivity of the calculated from Weiner's mixing formula and the measured values are due to Kuroiwa [1956]. There is a systematic error in his measurement of the free water content. Ambach $(1963, p .174-77)$ has given results for snow of much lower density 
density. The results were published as deviations from the permittivity of dry snow, and there is clearly a systematic error in the measurement of free water content since there is a finite deviation when no measureable quantity of water is present; this is attributed to the inefficiency of the centrifugal separator used to extract the water. Ambach (1963, p. 174-77) has proposed that measurement of the dielectric constant could be used to estimate the free water content of snow. However, the magnitude of the effect depends greatly on the specific gravity of the dry snow (which will not usually be known) and on the effective value of the Formzahl.

The second consideration when impurities are present is the increased value of the directcurrent conductivity, $\sigma$. If the conductivity is known, or can be measured, then the contribution to the loss factor, $\epsilon^{\prime \prime}$, may be calculated from the relationship in Appendix C. Some figures are given for natural snow in Table I; Kopp lists the widest range of samples and temperatures but it is interesting to compare his figures with others derived by entirely independent means. Those for impure city snow have been estimated by the reverse process to that mentioned above - by taking the deviation of $\epsilon$ " from the semicircular form in ColeCole diagrams published by Kuroiwa for snow samples containing up to 30 parts per million of chloride ions among other impurities. The conductivity is high as would be expected. The low conductivities obtained by Watt and Maxwell for wet snow are more surprising, but they are believed to be entirely reliable since they are derived from consistent Cole-Cole plots measured with ELTRAN electrode arrays on the undisturbed material in the field. H. Röthlisberger reports (private communication) that it is now established that fine-grained Arctic snow has a higher conductivity than wet avalanche snow in Europe, for which values very close to those of Watt and Maxwell have been found.

\section{Table I. Direct-Current Electrical Conductivities}

\section{Material}

Pure ice

Soft new snow, density $0 \cdot 13 \mathrm{~g} . / \mathrm{cm} .^{3}$

Granular snow, density $0.4 \mathrm{~g} . / \mathrm{cm} .^{3}$

City snow, density $0 \cdot 4$ g. $/ \mathrm{cm}^{3}$

Compact wet snow, Colorado

Glacial ice, Alberta

Sea ice, salinity 0.5 per cent

Pure water

Distilled water

Public water supply

Sea-water

Ioo p.p.m. common salt solution

Dry sand or rock

Frozen earth, Antarctica

Partially frozen earth, Alaska

$\begin{array}{cc} & \begin{array}{c}\text { Estimated } \\ \text { relative }\end{array} \\ \text { Temperature Conductivity permittivity } \\ \text { C. } \quad \mathrm{mho} / \mathrm{m} .\end{array}$

$$
\begin{aligned}
& -10 \\
& -40 \\
& -10 \\
& -40 \\
& -10 \\
& -40
\end{aligned}
$$

0
-4
0
0
-7
-24

$$
\begin{gathered}
10^{-7} \\
3 \times 10^{-9} \\
10^{-9} \\
3 \times 10^{-11} \\
10^{-7} \\
10^{-9}
\end{gathered}
$$

$$
3 \times 10^{-5}
$$$$
3 \times 10^{-6}
$$$$
10^{-6}
$$$$
5 \times \mathrm{IO}^{-7}
$$$$
\mathrm{IO}^{-3}
$$$$
\mathrm{IO}^{-4}
$$$$
4 \times 10^{-6}
$$$$
2 \times 10^{-4}
$$$$
10^{-3}
$$$$
\text { to } 5 \times 10^{-2}
$$$$
\text { I to } 5
$$$$
2 \times 10^{-2}
$$$$
10^{-5}
$$$$
\text { to } \mathrm{IO}^{-4}
$$$$
-20
$$$$
5 \times 10^{-4}
$$$$
\sim 2 \times \mathrm{IO}^{-3}
$$

$$
\begin{aligned}
& \text { Frequency } \\
& \text { for } \\
& \text { tan } \delta=I \\
& \text { c./sec. }
\end{aligned}
$$

Reference

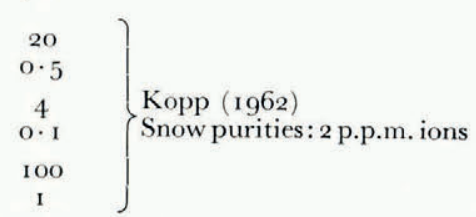

$$
\begin{array}{cc}
20 \times 10^{3} & \text { Kuroiwa [1956] } \\
3 \times 10^{3} & 20 \text { p.p.m. Cl ions } \\
500 & \text { Watt and Maxwell (1960) } \\
100 & \text { ( } \\
5 \times 10^{6} & \begin{array}{c}
\text { Dichtel and Lundquist } \\
(1951)
\end{array} \\
5 \times 10^{5} & (195)
\end{array}
$$

$\mathrm{I} \times \mathrm{IO}^{3}$

$4 \times 10^{4}$

$2 \times 10^{5}$

to $10^{7}$

$2 \times 10^{8}$

to $10^{9}$

$4 \times 10^{6}$

$2 \times 10^{4}$

to $2 \times 10^{5}$

10 $^{6}$
$4 \times 10^{6}$$\quad \begin{gathered}\text { Hatherton (1960) } \\ \text { Wescott and Hessler (1960) } \\ \text { Stanley (1958) }\end{gathered}$ 
In the absence of experimental values of the conductivity in the required circumstances the best that can be done is to set some limits to the effect. Thus the d.c. conductivities of various waters and other materials are also listed in Table I together with the approximate frequency below which the loss tangent is greater than unity, that is, where the effect of the d.c. conductivity cannot in any circumstances be ignored. The surprising result here is the high conductivity of frozen earth, however there is good agreement between entirely independent measurements.

In cold ice with carefully controlled amounts of impurity, Gränicher (1963) found that concentrations of the order of a hundred parts per million of suitable atoms can exist in solid solution before the crystal lattice is disarranged with separate crystals and bubbles appearing. At this point, the limit of miscibility, the conductivity can be increased to about $\mathrm{IO}^{-3}$ mho per metre. There are large changes in permittivity for much lower concentrations, when the conductivity is about $1^{-5}$ mho per metre and this shows in curve (c) in Figure $\mathrm{I}$. The conductivity and increased permittivity arise from lattice imperfections and the contribution of various types of imperfections have been discussed by Hasted (i96r).

\section{Radio Frequencies}

\section{I Permittivity: Ice}

Between a frequency of I Mc./sec. and the far infra-red region there is no absorption band in the spectrum of ice. We shall give the evidence for this statement below, but once the fact is established there is no further interest to the chemist in investigating the spectrum in the intervening region from the point of view of elucidating the crystal or molecular structure. The only incentive to experimental work is likely to come from a practical requirement for knowledge of the properties of ice or snow as a radio-frequency material in a particular application. One may be interested in radio propagation over snow-covered ground, over icecovered water, or the effects of icing on antenna and transmission-line parameters. Consequently the available measurements are not easily compared with one another since they relate to samples differing in temperature, density, composition, and mechanical stress, factors which are not always adequately specified.

Let us consider first the relative permittivity of pure solid ice as a function of frequency. Results are collected in Figure 6 where code letters identify the individual authorities, the temperature, and other remarks about the measurements. At frequencies of the order of I Mc./sec. we expect to observe the high frequency tail of the relaxation spectrum, and this will be sensitive to temperature, the coefficient decreasing to zero with increasing frequency. The measurements of Lamb and Auty and Cole seem to represent the most recent and careful laboratory work on pure ice free from residual stress. The highest frequency plotted by Auty and Cole is $5^{\circ} \mathrm{kc}$./ $/ \mathrm{sec}$. and the curve in Figure 6 is extrapolated to their published value of high-frequency permittivity using the Debye formula. Lamb's measurements refer to a slightly higher temperature but the real difference between the two lies in the limiting values of the permittivity at high frequency, $\epsilon_{\infty}=3 \cdot 10$ and $3 \cdot 17$ respectively. Lamb found the same value, 3.17 , at $10,000 \mathrm{Mc}$. $/ \mathrm{sec}$. and $24,000 \mathrm{Mc}$. $/ \mathrm{sec}$. with negligible temperature coefficient in the range $0^{\circ}$ to $-190^{\circ} \mathrm{C}$. Cumming's results, $3 \cdot{ }^{1} 5$ at 9,375 Mc./sec., and Von Hippel's results, 3.17 at $10,000 \mathrm{Mc}$. $/ \mathrm{sec}$. and 3.20 at $3,000 \mathrm{Mc}$. $/ \mathrm{sec}$, , are all in good agreement.

Uncertainty arises in the intermediate range, I to $\mathrm{I}, 000 \mathrm{Mc}$./sec., where the measurements of Von Hippel on pure ice made in the laboratory from conductivity water, and recent measurements of Yoshino made in the Antarctic, lie much higher than would be expected from the results on either side. Westphal (private communication) states that Von Hippel's measurements were made hurriedly during wartime and the samples contained residual stresses and temperature gradients due to the method of freezing. It is not known how large an effect this can produce, but, if it is serious, the agreement with Yoshino is surprising. 


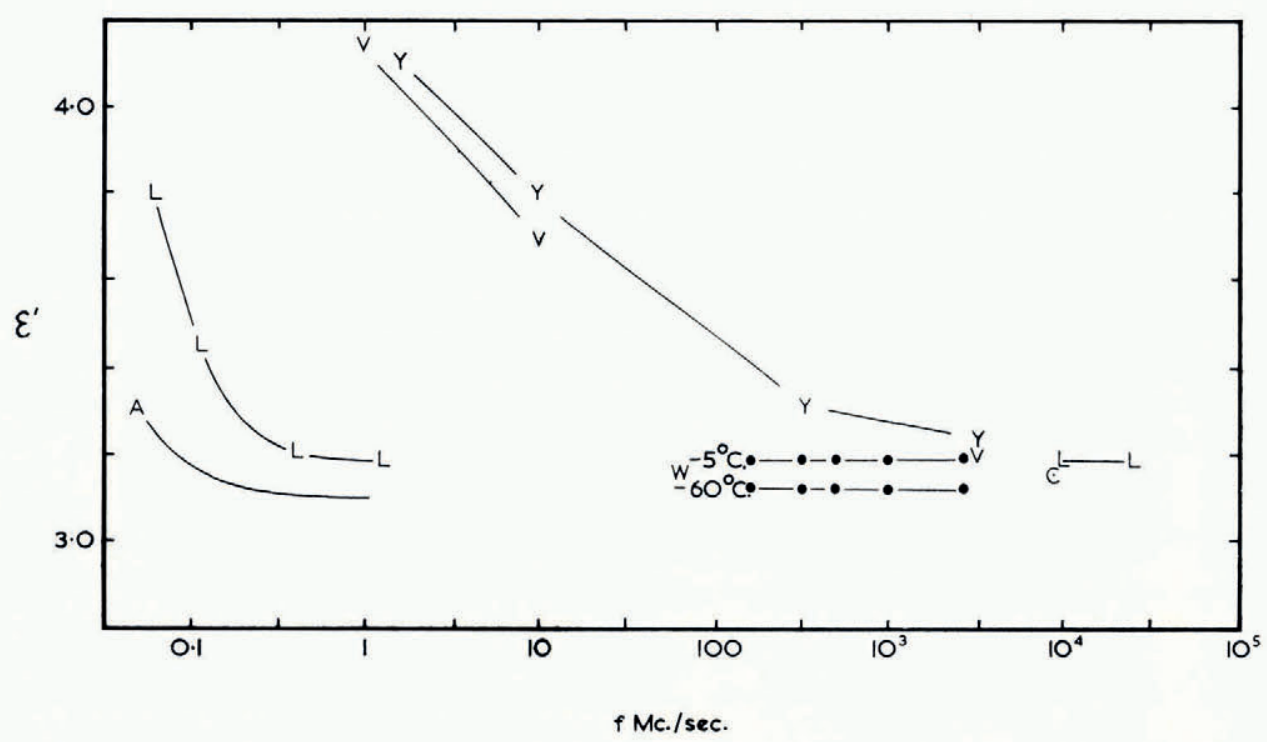

Fig. 6. Relative permittivity of ice (ordinates) versus logarithm of radio-frequency (abscissae) L: Lamb $(1946)$ and Lamb and Turney $(1949)-5^{\circ} \mathrm{C}$. at low frequencies, $o^{\circ}$ to $-190^{\circ} \mathrm{C}$. at high frequencies: distilled
water.

C: Cumming $(1952)-18^{\circ} \mathrm{C}$. Distilled water and melted snow.

A: Auty and Cole $(1952)-10^{\circ} \mathrm{C}$. Conductivity water: ice free from stress.

$V$ : Von Hippel (1954) $-12^{\circ} \mathrm{C}$. Conductivity water: ice not annealed.

$r$ : Yoshino $(196 \mathrm{I})-18^{\circ}$ to $-36^{\circ} \mathrm{C}$. Antarctic ice, not annealed, density $0.9 \mathrm{I} \mathrm{g} .1 \mathrm{~cm} .^{3}$

W: Westphal (private communication) $-5^{\circ} t 0-60^{\circ} \mathrm{C}$, annealed Greenland ice, density $0.90 \mathrm{~g} . / \mathrm{cm} .{ }^{3}$

Clearly, more measurements are desirable under a variety of conditions in this frequency range, but until they are available we conclude that the values of permittivity due to Von Hippel and Yoshino are too high. Westphal's recent measurements (previously unpublished) on natural ice core samples of specific gravity 0.90 from the Greenland Ice Sheet, are in agreement with this view. He found it necessary, after machining the samples to fit the measuring apparatus, to anneal them for several hours at $-5^{\circ} \mathrm{C}$. in order to obtain reproducible results, but the presence of naturally occurring impurities has had no apparent effect. The temperature coefficient of permittivity at $24,000 \mathrm{Mc}$. $/ \mathrm{sec}$. is 0.024 per cent per ${ }^{\circ} \mathrm{C}$. which is higher than found by Cumming or Lamb at I0,ooo Mc./sec. Westphal's measurements on glacier ice cores (density $0.87 \mathrm{~g} . / \mathrm{cm} .{ }^{3}$ ) and sea-ice samples (density $0.9^{2} \mathrm{~g} . / \mathrm{cm} .{ }^{3}$ ) have been tabulated by Ragle, Blair and Persson (1964). There is no significant difference from the above results except that the permittivity of the less dense material is slightly less than that of solid ice.

\subsection{Permittivity: Snow}

The treatment of a mixture of dielectrics given earlier is entirely applicable in this frequency range and some of the results for high-frequency permittivity plotted in Figure 4 (b) are due to Cumming at $9,375 \mathrm{Mc}$./sec. The curves are computed for different Formzahl assuming the permittivity of solid ice to be 3.20 and, bearing in mind the uncertainty in this value, Figure 4 (b) may be used at all frequencies from io Mc./sec. to 30,000 Mc./sec. The curves for $u=2$ and $u=\infty$ represent the limits beyond which natural snow is unlikely to lie. 


\subsection{Loss tangent: Ice}

At frequencies much higher than the relaxation frequency the quantity $\omega \epsilon^{\prime}$ is constant if there are no contributions from other absorption bands. In Figure 7 we plot the more convenient practical quantity, $f \tan \delta$, where $f$ is the frequency in Mc./sec.; the sources of information are given in the legend. Again, the measurements of Westphal on annealed ice core samples from Greenland may be joined smoothly to the high-frequency limiting values derived from the relaxation spectra of pure ice measured by Lamb, and by Auty and Cole. Since the high-frequency tail of the relaxation spectrum makes its presence felt at higher frequencies the higher the temperature, we have chosen to plot the limiting values arbitrarily at $\mathrm{I}, 000$ times the relaxation frequency at different temperatures. The tail of the infra-red absorption spectrum may add to the residual value of $f \tan \delta$ from the relaxation spectrum in this range and our choice is justified by the fact that the losses due to the relaxation spectrum evidently account for the whole of the observed loss at $0^{\circ} \mathrm{C}$. up to about $300 \mathrm{Mc}$. $/ \mathrm{sec}$. In the absence of other information, the values measured by Yoshino seem to be much too high; it should be remembered that any unforeseen errors in the experimental technique may increase the losses but they cannot in any circumstances be expected to result in measured loss less than the true value. At the high frequencies Westphal's values may be joined smoothly to those of Lamb, except that Lamb (and Cumming, whose results are systematically higher at all temperatures) found $\tan \delta$ to increase more sharply with temperature just below the melting point.

Estimates of the absorption of radio echoes obtained through the Greenland Ice Sheet at $35 \mathrm{Mc}$. $/ \mathrm{sec}$. and $440 \mathrm{Mc}$./sec. appear to be in good agreement with Figure 7. There are uncertainties in the reflection coefficient of the bottom of the ice sheet and in the temperature distribution within the ice and a more detailed assessment of this particular problem will be given elsewhere.

The general impression created by Figure 7 is that the increase of $f \tan \delta$ which begins at a few hundred megacycles is due to an infra-red absorption process which is not very temperature sensitive. Thus the infra-red contribution is felt first at the lower temperatures where the residual contribution to $f \tan \delta$ from the relaxation spectrum is lower. At $10 \mathrm{~cm}$. wavelength or less, the majority of the absorption is due to the infra-red bands and the temperature coefficient is small. This view is in agreement with that of Lamb, who extended his measurements at $24,000 \mathrm{Mc}$. $/ \mathrm{sec}$. ( $1 \cdot 25 \mathrm{~cm}$. wavelength) down to $-190^{\circ} \mathrm{C}$. to search for evidence of an absorption process where the resonant frequency was reduced by reducing the temperature. He concluded that it must be at a very much shorter wavelength than $\mathrm{I} \mathrm{cm}$. throughout his temperature range, and pointed out that the whole infra-red absorption spectrum must account for the difference between $\epsilon^{\prime}=3 \cdot 17$ at $1 \mathrm{~cm}$. wavelength, and the square of the optical refractive index, $n^{2}=1 \cdot 72$.

The infra-red transmission of individual ice crystals and polycrystalline films has been given by Ockman (1958) who found broad absorption bands from wave-numbers of $5^{00 \mathrm{~cm}} .^{-1}$ up to $10,000 \mathrm{~cm}^{-1}$ (I micron wavelength). Over most of the range temperature changes had no significant effect but at the lowest frequencies there was a small decrease in the absorption as the temperature was reduced from $-30^{\circ} \mathrm{C}$. to $-175^{\circ} \mathrm{C}$.; it is possible that there are unexplored absorption bands in the range 10 to $100 \mathrm{~cm}^{-1}$.

\subsection{Loss tangent: Snow}

Weiner's formula, equation (3), may be used to find both the relative permittivity and the loss factor of a mixture, by separating the formula into real and imaginary parts. Unless some simplifying approximations can be made, the algebra is rather cumbersome and we restrict ourselves first to the case where medium 2 is air, and medium $\mathrm{I}$ is ice for which $\tan ^{2} \delta \ll \mathrm{I}$; this is always true at frequencies greater than I Mc./sec. Then the real part of the formula 


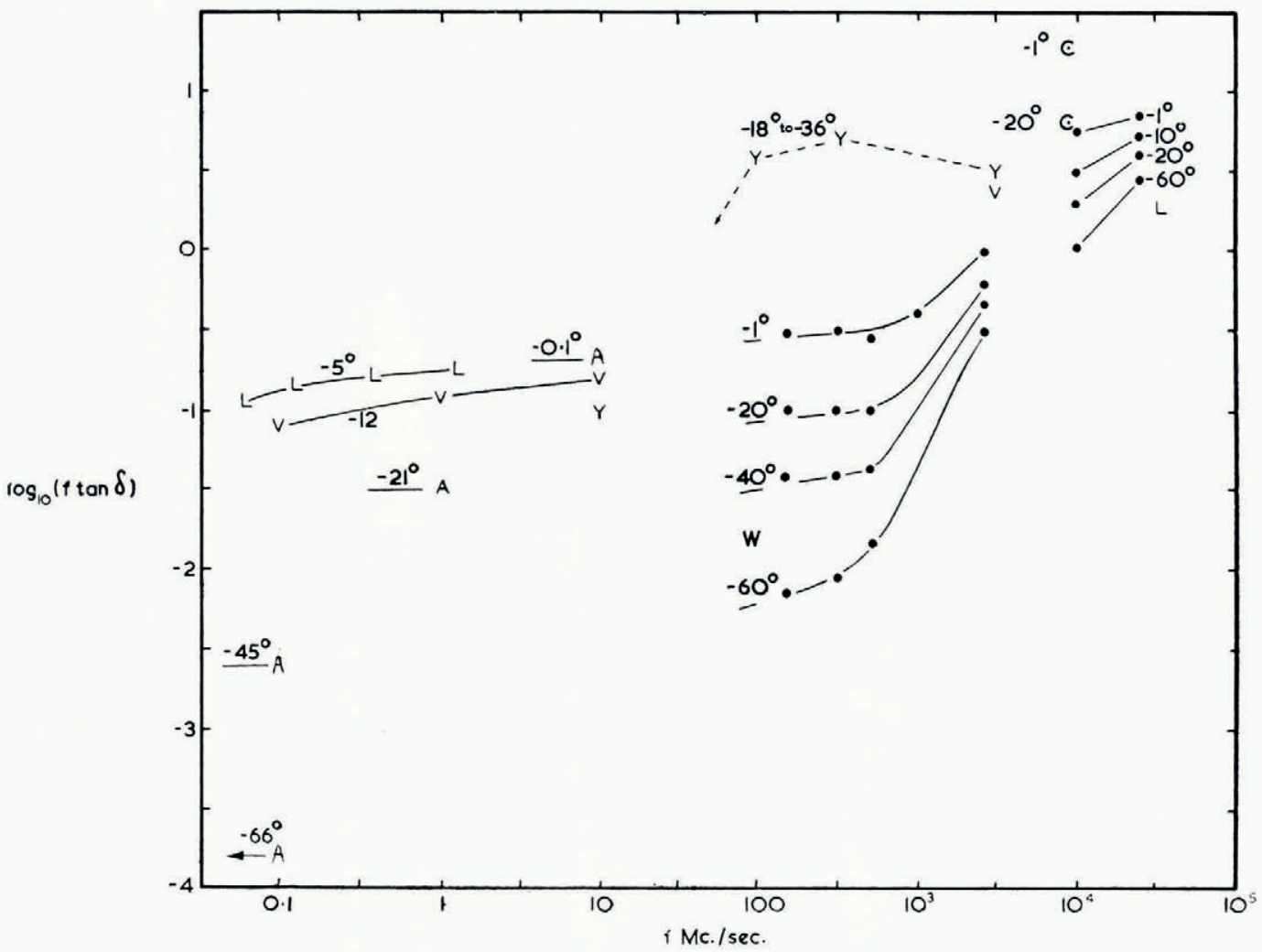

Fig. 7. Loss tangent of ice versus radio-frequency. The quantity plotted vertically is $\log _{\mathrm{1}}(f$ tan $\delta)$ where $f$ is the frequency in Mc. $/ \mathrm{sec}$. On the high-frequency tail of a relaxation spectrum this quantity is constant: it has the further useful property that the attenuation of a radio wave (measured in $d B$./m.) passing through the medium is directly proportioned to f tan $\delta$, see Appendix C. Temperatures are marked in ${ }^{\circ} \mathrm{C}$.

L: Lamb (1946) and Lamb and Turney (1949) Distilled water, ice not annealed.

C: Cumming (1952) Distilled water, tap water, and melted snow (no observable difference).

A: Auty and Cole (1952) Conductivity water, ice free from stress. Limiting values plotted arbitrarily at I, ooo times the relaxation frequency.

V: Von Hippel (1954) Conductivity water, ice not annealed.

Y: Yoshino (196I) Antarctic ice core samples, not annealed, density $0.9 \mathrm{I} \mathrm{g.} / \mathrm{cm}^{3}$

W: Westphal (private communication) Greenland ice, annealed, density $0.90 \mathrm{~g} . / \mathrm{cm} .^{3}$

Approximate temperature coefficients below $-10^{\circ} \mathrm{C}$.

I Mc. $/$ sec. $0.0_{5}$ per ${ }^{\circ} \mathrm{C}$. in $\log \tan \delta=12 \%$ per ${ }^{\circ} \mathrm{C}$. in tan $\delta$ (from Auty and Cole)

Ioo Mc. $/ \mathrm{sec} .0 .025$ per ${ }^{\circ} \mathrm{C}$. in $\log \tan \delta=6 \%$ per ${ }^{\circ} \mathrm{C}$. in tan $\delta$ (from Westphal)

IO $\mathrm{O}^{4} \mathrm{Mc}$. $/ \mathrm{sec}$. $\mathrm{O} . \mathrm{OI}$ per ${ }^{\circ} \mathrm{C}$. in $\log \tan \delta=2.5 \%$ per ${ }^{\circ} \mathrm{C}$. in tan $\delta$ (from Lamb)

is identical with equation (3) substituting only the real parts of the permittivity for $\epsilon$ throughout. From the imaginary part

$$
\epsilon_{s}^{\prime \prime}=\epsilon_{i}^{\prime \prime} \frac{\mathrm{I}}{p}\left(\frac{\epsilon_{s}^{\prime}-\mathrm{I}}{\epsilon_{i}^{\prime}-\mathrm{I}}\right)^{2}
$$

Suffix $i$ refers to medium I (ice) and suffix $s$ to the mixture (snow). The proportion of ice by volume is denoted by $p$. Note that this does not contain the Formzahl directly, but it does assume, as previously, that a single value of $u$ is sufficient for all proportions of mixture and it contains the relative permittivity of the mixture which could be computed for an assumed 
value of $u$, or for which experimental values may be substituted directly. This latter method has been used for Cumming's measurements plotted in Figure 8. They lie very close to the computed curve for $u=2$ and it is unfortunate that no other measurements of loss tangent versus density seem to have been made. As a rough working rule, we can say that if the density is $0.5 \mathrm{~g} . / \mathrm{cm} .^{3}$ the losses are halved.

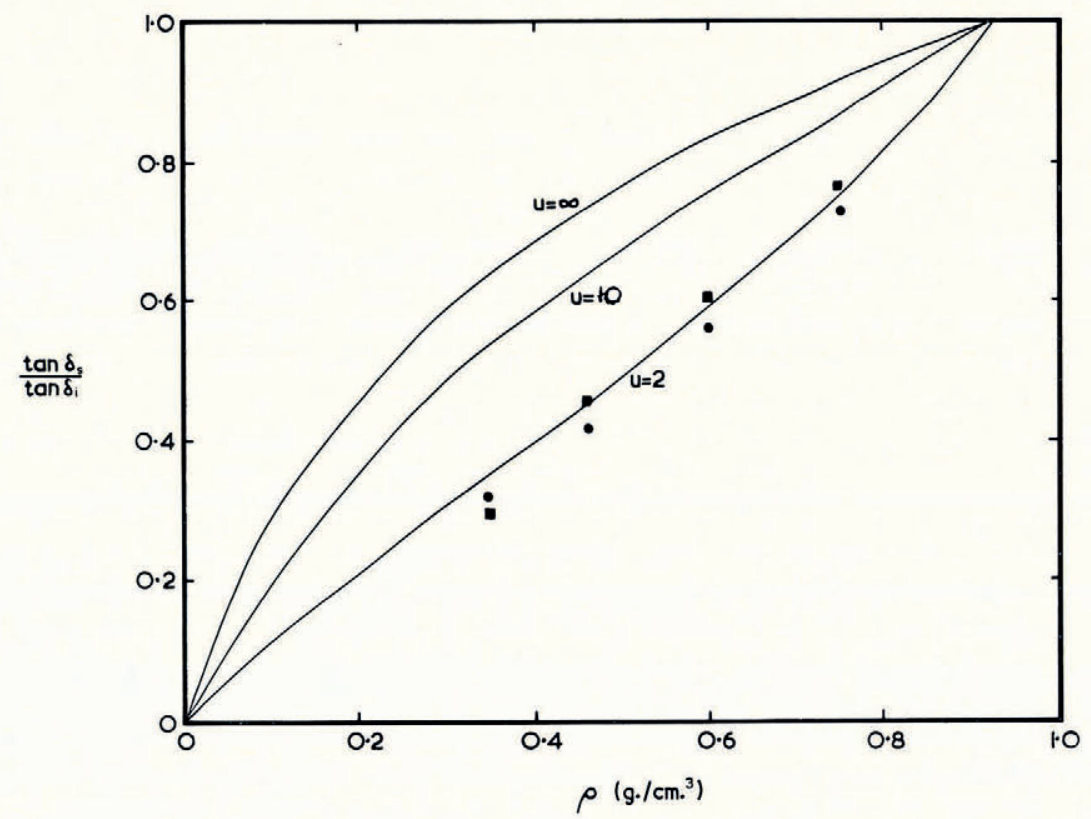

Fig. 8. Loss tangent of snow versus density (abscissae). The quantity plotted vertically is the ratio of the loss tangent of the ice/air mixture forming snow to that of the solid ice. Smooth curves are plotted for different values of the Formzahl in Weiner's formula assuming that tan $\delta$ is much less than unity for the solid ice considered. Measured values are due to Cumming (1952) at $9,375 \mathrm{Mc} . / \mathrm{sec} .$, at $o^{\circ} \mathrm{C} ., \mathbf{\square}$ at $-8^{\circ} \mathrm{C}$.

\subsection{Effect of impurities and free water}

Westphal's measurements on glacier ice from Ellesmere Island (Ragle and others, I964) although of slightly lower density do not differ significantly from the Greenland samples. However sea-ice cores have a loss tangent which is consistently about twenty times greater than the Greenland samples from 100 to $3,000 \mathrm{Mc}$. $/ \mathrm{sec}$. and $\mathrm{o}^{\circ}$ to $-60^{\circ} \mathrm{C}$.

A small proportion of liquid water can have widely varying effects on the loss tangent of snow. Water has a relaxation spectrum in which the loss factor reaches a maximum at approximately $10,000 \mathrm{Mc}$. $/ \mathrm{sec}$. at $0^{\circ} \mathrm{C}$. but possibly more important in many cases is the d.c. conductivity of the water and its contribution to the loss factor at low frequencies as discussed in section I.3. Table I gives the frequency for which the loss tangent is unity for various impure waters; note that at a frequency $n$ times greater than that tabulated, the loss tangent will have fallen to $\mathrm{I} / n$. Thus, estimating the loss factor of the water concerned, we wish to know its contribution to the loss in wet snow. We use the imaginary part of Weiner's formula with the simplifying assumptions that the loss tangent of the water is not greater than unity, and that the proportion of water is less than i per cent.

Then we have

$$
\begin{gathered}
\epsilon_{w s}^{\prime}=\epsilon_{s}^{\prime} \\
\epsilon_{w s}^{\prime \prime} \approx p \epsilon_{w}^{\prime \prime}\left[\mathrm{I}+2 \epsilon_{w}^{\prime \prime} /\left(\epsilon_{w}^{\prime}+u\right)\right] .
\end{gathered}
$$$$
\text { and }
$$

The factor in square brackets will usually be negligible. 
As an example, the purest public water supply would have a loss tangent of approximately $2 \times 10^{-3}$ at $100 \mathrm{Mc}$. $/ \mathrm{sec}$. and therefore a relative loss factor, $\epsilon_{w}^{\prime \prime}=0 \cdot 2$. A I per cent proportion of this water would contribute to the loss factor of wet snow $\epsilon_{w s}^{\prime \prime} \sim 2 \times 10^{-3}$ increasing $f \tan \delta$ by $\sim 0 \cdot \mathrm{I}$ Mc./sec. This is probably less than $f \tan \delta$ for the dry snow at $o^{\circ} \mathrm{C}$. and the effect is negligible. However, by the same method of estimation, a I per cent proportion of low salinity sea-water under the same conditions would make the loss tangent of the wet snow greater than unity.

Cumming made measurements of the loss tangent of snow versus free water content at $9,375 \mathrm{Mc}$./sec., where the losses would be due predominantly to the relaxation spectrum of water. His results are shown in Figure 9 and in order to account for the magnitude of the observed effect by our equation (5) we require the relative loss factor of the water alone, $\epsilon_{w}^{\prime \prime}$ to be $\sim 2$ which is reasonable at this frequency.

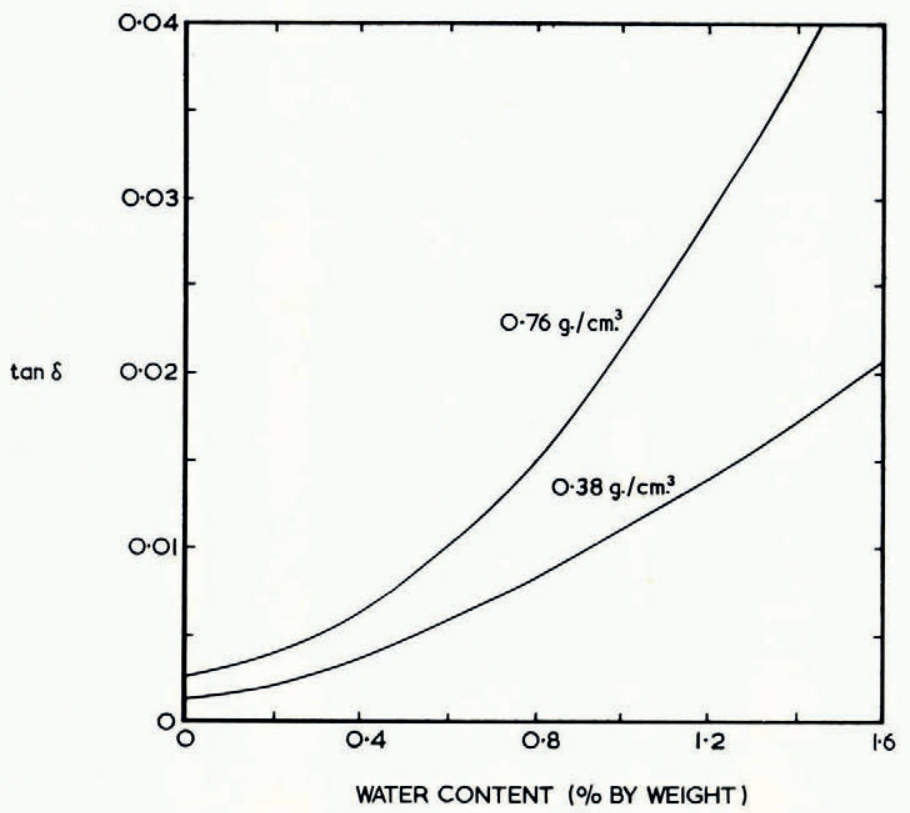

Fig. 9. Loss tangent of snow (ordinates) versus free water content in per cent by weight (abscissae). Mean curves are shown for two snow samples of density 0.76 and $0.3^{8} \mathrm{~g} . / \mathrm{cm} .{ }^{3}$, temperature $o^{\circ} \mathrm{C}$., radio frequency $9,375 \mathrm{Mc} . / \mathrm{sec}$. (after Cumming, $195^{2}$ )

\section{Conclusions}

We have shown that pure ice has a relaxation spectrum, related to temperature, but more measurements are needed on naturally occurring snow and ice. It may then be possible to develop a technique for temperature measurement in deep ice by investigating the relaxation spectrum with electrodes on the surface.

The V.H.F. range, from 30 to $300 \mathrm{Mc}$./sec., has recently become of interest because of the possibility of propagating radio signals of this frequency through large bodies of natural snow and ice. Appreciable uncertainty remains in the value of the loss tangent since we have only Westphal's measurements on isolated samples and very little evidence of the variability of the natural material. Using his measurements on Greenland ice near roo Mc./sec. we should expect the attenuation of a radio signal to be approximately $5 \mathrm{~dB}$. per $100 \mathrm{~m}$. at $0^{\circ} \mathrm{C}$. and 
$0.5 \mathrm{~dB}$. per $100 \mathrm{~m}$. at $-40^{\circ} \mathrm{C}$. Thus signals could be propagated, and their source located, through glaciers at $0^{\circ} \mathrm{C}$. provided they did not contain too much water. At the lowest temperatures we could expect to propagate detectable signals through the thickest parts of the Antarctic Ice Sheet. It is interesting to note that the possibility of measuring glacier depths by radio techniques was proposed, and some modest success attained by Stern on the Hochvernagtferner, as early as 1927. This, and the present-day possibilities, have been reviewed by Evans ( 1963 ).

\section{MS. received 24 April 1964 and in revised form 4 fanuary 1965}

\section{REFERENCES}

Ambach, W. 1963. Untersuchungen zum Energieumsatz in der Ablationzone des grönländischen Inlandeises (Camp IV-EGIG, $69^{\circ} 40^{\prime} 05^{\prime \prime} \mathrm{N}, 49^{\circ} 37^{\prime} 58^{\prime \prime} \mathrm{W}$ ). Meddelelser om Gronland, Bd 1 74, Nr. 4 .

Auty, R. P., and Cole, R. H. 1952. Dielectric properties of ice and solid $\mathrm{D}_{2} \mathrm{O}$. Journal of Chemical Physics, Vol. 20, No. 8, p. ${ }^{1} 309^{-1} 4$.

Brill, R. 1957. Structure of ice. U.S. Snow, Ice and Permafrost Research Establishment. Report 33.

Cole, K. S., and Cole, R. H. 1941. Dispersion and absorption in dielectrics. I. Alternating current characteristics. Fournal of Chemical Physics, Vol. 9, No. 4, p. 341-51.

Cumming, W. A. 1952. The dielectric properties of ice and snow at 3.2 centimeters. Fournal of Applied Physics, Vol. 23, No. 7, p. $768-73$.

Dichtel, W. J., and Lundquist, G. A. 1951. An investigation into the physical and electrical characteristics of sea ice. Bulletin of the National Research Council of the U.S., No. 122, p. 122. [Abstract.]

Evans, S. I963. Radio techniques for the measurement of ice thickness. Polar Record, Vol. i I, No. 73, p. 406-10; No. 75 , p. 795 .

Gränicher, H. 1963 . Properties and lattice imperfections of ice crystals and the behaviour of $\mathrm{H}_{2} \mathrm{O}-\mathrm{HF}_{\mathrm{F}}$ solid solutions. Physik der kondensierten Materie, Bd. I, Ht. I, p. I-I 2.

Gränicher, H., and others. I 957 . Dielectric relaxation and the electrical conductivity of ice crystals, by H. Gränicher, C. Jaccard, P. Scherrer and A. Steinemann. Discussion of the Faraday Society, No. 23, p. 50-62.

Hasted, J. B. 1961. The dielectric properties of water. Progress in Dielectrics, Vol. 3. p. Io I-49.

Hatherton, T. ig6o. Electrical resistivity of frozen earth. Fournal of Geophysical Research, Vol. 65, No. 9, p. 3023-24.

Humbel, F., and others. 1953. Anisotropie der Dielektrizitätskonstante des Eises, von F. Humbel, F. Jona und P. Scherrer. Helvetica Physica Acta, Vol. 26, Fasc. 1, p. 17-32.

Kopp, M. 1962. Conductivité électrique de la neige, au courant continu. Zeitschrift für angewandte Mathematik und Physik, Bd. 13, Ht. 5, p. 43 I-41.

Kuroiwa, D. [1956.] The dielectric property of snow. Union Géodésique et Géophysique Internationale. Association Internationale d'Hydrologie Scientifique. Assemblée générale de Rome 1.954, Tom. 4, p. 52-63.

Lamb, J. 1946. Measurements of the dielectric properties of ice. Transactions of the Faraday Societ), Vol. 42A, p. $238-44$.

Lamb, J., and Turney, A. I949. The dielectric properties of ice at $1 \cdot 25 \mathrm{~cm}$. wavelength. Proceedings of the Physical Society, Sect. B, Vol. 62, Pt. 4, p. 272-73.

Ockman, N. 1958. The infra-red and Raman spectra of ice. Advances in Physics, Vol. 7, No. 26, p. 199-220.

Powles, J. G. 1952. A calculation of the static dielectric constant of ice. Fournal of Chemical Physics, Vol. 20, No. 8, p. $1302-09$.

Ragle, R. H., and others. 1964. Ice core studies of Ward Hunt Ice Shelf, ig6o, by R. H. Ragle, R. G. Blair and L. E. Persson. Journal of Glaciology, Vol. 5, No. 37, p. 39-59.

Sillars, R. W. 1937. The properties of a dielectric containing semi-conducting particles of various shapes. Journal of the Institution of Electrical Engineers, Vol. 8o, No. 484, p. 378-94.

Stanley, G. M. 1958. Studies of ground conductivity in the Territory of Alaska. University of Alaska. Geophysical Report Series, UAG-R81.

Vieweg, R., and Gast, T. 1943. Ein Beitrag zur Ermittlung der Dielektrizitätskonstanten von Mischkörpen. Zeitschrift für Technische Physik, [Bd.] 24, Nr. 3, p. 56-62.

Von Hippel, A., ed. 1954. Dielectric materials and applications. Cambridge, Mass., Technology Press of Massachusetts Institute of Technology; New York, John Wiley and Sons, Inc.; London, Chapman and Hall, Ltd.

Wagner, K. W. r9i3. Zur Theorie der unvolkommenen Dielektrika. Annalen der Physik, 4. Folge, Bd. 40, No. 5, p. $817-55$.

Watt, A. D., and Maxwell, E. L. 196o. Measured electrical properties of snow and glacial ice. Fournal of Research of the National Bureau of Standards (Washington, D.C.), Sect. D, Vol. 64, No. 4, p. 357-63.

Weiner, O. 1910. Zur Theorie der Refraktionskonstanten. Berichte über die Verhandlungen der Königlich Sächsischen Gesellschaft der Wissenschaften zu Leipzig. Mathematisch-physikalische Klasse, Bd. 62, Ht. 5, p. $256-68$.

Wescott, E. M., and Hessler, V. P. 1960. The effect of topography and geology on telluric currents. University of Alaska. Geophysical Report Series, UAG-R 107.

Yoshino, T. I961. Radio wave propagation on the ice cap. Antarctic Record (Tokyo), No. I I, p. $228-33$. 


\section{APPENDIX A}

\section{Chronological Annotated Bibliography of Published Measurements}

Errera, M. J. 1924. La dispersion des ondes hertziennes dans les solides au voisinage du point de fusion. Fournal de Physique et le Radium, Sér. 6, Tom. 5, No. 10, p. 304-1 I. [Frequencies up to $300 \mathrm{kc} . / \mathrm{sec}$. and temperatures down to $-47^{\circ} \mathrm{C}$.]

Granier, J. 1924. Absorption des ondes électromagnétiques par la glace. Comptes Rendus Hebdomadaires des Séances de l'Académie des Sciences (Paris), Tom. 179, No. 23, p. 1313-16. [Early measurements. Frequencies up to $7 \mathrm{Mc}$./sec. and temperatures down to $-30^{\circ} \mathrm{C}$.]

Lenaizon, B. de, and Granier, J. 1925 . Sur le pouvoir inducteur spécifique de la glace. Comptes Rendus Hebdomadaires des Séances de l'Académie des Sciences (Paris), Tom. I80, No. 3, p. 198-99. [83 Mc./sec., - $\left.4{ }^{\circ} \mathrm{C}.\right]$

Murphy, E. J., and Lowry, H. H. 1930. The complex nature of dielectric absorption and dielectric loss. Journal of Physical Chemistry, Vol. 34, No. 3, p. 598-620. [In crystalline dielectrics the ions which take part in conduction are concentrated in lattice imperfections.]

Smyth, C. P., and Hitchcock, C. S. 1932. Dipole rotation in crystalline solids. Fournal of the American Chemical Society, Vol. 54, No. 12, p. 4631-47. [Measurements on ice made from conductivity water up to $60 \mathrm{kc}$. $/ \mathrm{sec}$. and down to $-70^{\circ} \mathrm{C}$.]

Wintsch, H. I932. Uber Dielektrizitätskonstante, Widerstand, und Phasenwinkel des Eises. Helvetica Physica Acta, Vol. 5, Fasc. 2, p. 126-44. [Table of earlier measurements. New measurements up to $8 \mathrm{kc}$./sec., down to $-50^{\circ} \mathrm{C}$.]

Murphy, E. J. I934. The temperature dependence of the relaxation time of polarizations in ice. Transactions of the Electrochemical Society, Vol. 65 , p. ${ }_{1} 33^{-42}$. [Measurements down to $-190^{\circ} \mathrm{C}$. and from a relaxation time of $20 \mathrm{sec}$. to $100 \mathrm{kc} . / \mathrm{sec}$.]

Murphy, E. J., and Morgan, S. O. 1939. The dielectric properties of insulating materials. Pt. III. Bell System Technical Fournal, Vol. 18, No. 3, p. 502-37. [Results further to Murphy (1934) leading to double term expression for conductivity versus temperature.]

Dorsey, N. E. 1940. Properties of ordinary water-substance in all its phases: water-vapor, water and all the ices. New York, Reinhold Publishing Corporation. (American Chemical Society. Monograph Series, No. 8r.) [Collected data for all properties of water.]

Lamb, J. 1946. Measurements of the dielectric properties of ice. Transactions of the Faraday Society, Vol. 42A, p. $23^{8}-44$. [Measurements at $10,000 \mathrm{Mc}$. $/ \mathrm{sec}$. from $\mathrm{o}^{\circ}$ to $-4^{8} \mathrm{C}$. and at $-5^{\circ} \mathrm{C}$. from $8 \mathrm{kc}$. $/ \mathrm{sec}$. to $\mathrm{I} \cdot 25 \mathrm{Mc}$. $/ \mathrm{sec}$.]

Eder, F. X. 1947. Das elektrische Verhalten von Eis. Annalen der Physik, 6. Folge, Bd. 1, Ht. 7-8, p. 381-98. [Measurements down to $-50^{\circ} \mathrm{C}$., up to $3,000 \mathrm{Mc}$. $/ \mathrm{sec}$, but no results plotted for frequencies greater than Io Mc./sec.]

Averbukh, R. Ye., and Kosman, M. S. 1949. O polyarizatsii l'da [On the polarization of ice]. Zhurnal Eksperimental'noy $i$ Teoreticheskoy Fiziki [Journal of Experimental and Theoretical Physics], Tom 19, Vyp. 1 1, p. $97 \mathrm{I}-72$. [Static dielectric constant measurements at high field strengths.]

Jackson, W., and Saxton, J. A. I949. High-frequency absorption phenomena in liquids and solids. Proceedings of the Institution of Electrical Engineers, Vol. 96, Pt. 3, No. 40, p. 77-80. [General discussion. Contains no original measurements on ice.]

Lamb, J., and Turney, A. 1949. The dielectric properties of ice at $1 \cdot 25 \mathrm{~cm}$. wavelength. Proceedings of the Physical Society, Sect. B, Vol. 62, Pt. 4, p. 272-73. [Letter. Dielectric constant and loss tangent measured down to $-195^{\circ}$ C.]

Murphy, E. J. 1950. Alternating current conduction in ice. Physical Review, Ser. 2, Vol. 79, No. 2, p. 396-97. [Letter. Derivation of the energy of the hydrogen bond in ice, from the limiting conductivity.]

Saxton, J. A. 1950. Reflection coefficient of snow and ice at V.H.F. Wireless Engineer, Vol. 27, No. 316, p. 1 7-25. [Computed effects based mainly on Lamb's measurements.]

Dichtel, W. J., and Lundquist, G. A. 1951. An investigation into the physical and electrical characteristics of sea ice. Bulletin of the National Research Council of the U.S., No. 122, p. 122. [Abstract only. Samples from Point Barrow. Salinities between 3.5 and 7 parts per thousand. Cook (1960) quotes numerical results not given in the abstract.]

Kuroiwa, D. 1951. Sekisetsu no yūden-teki seishitsu [The dielectric behaviour of snow cover]. Teion-kagaku [Low Temperature Science], Ser. A, No. 8, p. 1-58. [Departures from a relaxation spectrum at low frequencies are attributed to impurities. The relaxation time of snow is found to be less than that of ice. English summary, text in Japanese, many diagrams.]

Murphy, E. J. I95I. The concentration of molecules on internal surfaces in ice. Fournal of Chemical Physics, Vol. 19, No. 12 , p. $1516-18$. [Deductions from temperature dependence of conductivity.]

Schellman, J. A. 195I. Dielectric properties of ice. Princeton University. Doctoral dissertation Series, Publication $5 \mathrm{I} 63$. [Calculations of the microscopic electric field for an aggregate of atoms in tetrahedral arrangements.]

Schellman, J. A., and Kauzmann, W. 1951. The dielectric polarization of ice. Physical Review, Ser. 2, Vol. 82, No. 2, p. 315. [Abstract only. Discussion of the relative configuration of neighbouring molecules, the electrostatic energy, and the resulting permittivity.]

Auty, R. P., and Cole, R. H. 1952. Dielectric properties of ice and solid $\mathrm{D}_{2} \mathrm{O}$. Fournal of Chemical Physics, Vol. 20, No. 8, p. ${ }^{1} 309^{-14}$. [Carefully controlled measurements on pure ice up to roo kc./sec. and down to $-66^{\circ} \mathrm{C}$.]

Cumming, W. A. 1952. The dielectric properties of ice and snow at 3.2 centimeters. Fournal of Applied Physics, Vol. 23 , No. 7, p. 768-73. [Variations with density down to $0.2 \mathrm{~g} . / \mathrm{cm} .^{3}$, temperature down to $-20^{\circ} \mathrm{C}$., and free water content up to $\mathrm{I} \cdot 5$ per cent.] 
Haggis, G. H., and others. 1952. The dielectric properties of water in solutions, [by] G. H. Haggis, J. B. Hasted and T. J. Buchanan. Fournal of Chemical Physics, Vol. 20, No. 9, p. 1452-65. [The static dielectric constant of ice at $\mathrm{O}^{\circ} \mathrm{C}$. is calculated.]

Hasted, J. B. r953. Étude des molécules d'eau par les radiofréquences. Fournal de Chimie Physique, Tom. 50, No. 7-8, p. 35-39. [The variation of relaxation frequency with temperature is related to the number of bands.]

Horigan, F. D. 1953. Electrical characteristics of snow and ice-a literature search. U.S. Technical Library of the Ouartermaster Research and Development Laboratories, Bibliographic Series, No. 28. [Bibliography for 1948-53. Some omissions.]

Humbel, F., and others. I 953. Anisotropie der Dielektrizitätskonstante des Eises, von F. Humbel, F. Jona und P. Scherrer. Helvetica Physica Acta, Vol. 26, Fasc. 1, p. 17-32. [Single crystals measured parallel and perpendicular to the optic axis at $\mathrm{I} \mathrm{kc} . / \mathrm{sec}$. down to $-40^{\circ} \mathrm{C}$.]

Truby, F. K. 1953. Some electrical hysteresis properties of ice. Physical Review, Ser. 2, Vol. 92, No. 2, p. 543-44. [Abstract only. Rectifying properties at high field strengths.]

Drost-Hansen, W., and Workman, E. J. 1954. Theory of volume rectification in ice. Physical Review, Ser. 2, Vol. 94, No. 3, p. 770 . [Abstract only. Front to back conductivity ratio $10^{5}$ in halide contaminated ice at low frequencies.]

Gränicher, H., and others. 1954. Erhöhung der Dielektrizitätskonstante des Eises durch Halogeneinlagerung, von H. Gränicher, P. Scherrer und A. Steinemann. Helvetica Physica Acta, Vol. 27, Fasc. 3, p. 21 7-19. [Experimental results.]

Von Hippel, A., ed. 1954. Dielectric materials and applications. Cambridge, Mass., Technology Press of Massachusetts Institute of Technology; New York, John Wiley and Sons, Inc.; London, Chapman and Hall, Ltd. [Contains measurements from $\mathrm{I} \mathrm{kc}$. $/ \mathrm{sec}$. to $3 \mathrm{~cm}$. wavelength on pure ice and two snow samples.]

Workman, E. J., and Drost-Hansen, W. 1954. The electrical conduction and dielectric properties of ice. Physical Review, Ser. 2, Vol. 94, No. 3, p. 770. [Abstract only. Highly co-ordinated electrical domains can give rise to very high static dielectric constant.]

Kuroiwa, D. [1956.] The dielectric property of snow. Union Géodésique et Géophysique Internationale. Association Internationale d'Hydrologie Scientifique. Assemblée générale de Rome 1.954, Tom. 4, p. 52-63. [Pure ice and natural snow from $\mathrm{I} \mathrm{kc}$./sec. to $100 \mathrm{kc}$. $/ \mathrm{sec}$. down to densities $0.1 \mathrm{~g} . / \mathrm{cm} .{ }^{3}$ and temperature $-9^{\circ} \mathrm{C}$.]

Riehl, N. 1956. Elektrische Leitfähigkeit von organischen Isolatoren, Eis und Proteinen im Zusammenhang mit der Energiewanderung. Naturwissenschaften, Jahrg. 43, Ht. 7, p. I $45-52$.

Zaromb, S. 1956. Proton jumps and the electrical behavior of ice and ice- $\mathrm{NH}_{4} \mathrm{~F}$ solutions. Fournal of Chemical Physics, Vol. 25, No. 2, p. $35^{0}-56$. [Includes discussion of relaxation times.]

Zaromb, S., and Brill, R. 1956 . Solid solutions of ice and $\mathrm{NH}_{4} \mathrm{~F}$ and their dielectric properties. Fournal of Chemical Physics, Vol. 24, No. 4, p. 895-902. [Experiments on the phase diagram and on the relaxation time.]

Bradley, R. S. 1957. The electrical conductivity of ice. Transactions of the Faraday Society, Vol. 53, Pt. 5, p. 687-9 r. [Direct current.]

Brill, R. 1957. Structure of ice. U.S. Snow, Ice and Permafrost Research Establishment. Report 33. [Possibility of solid solution up to ro per cent. Effect on relaxation spectrum.]

Brill, R., and Camp, P. 1957. Influence of pressure on the dielectric properties of ice. Nature, Vol. 179, No. 4560, p. 623-24. [Letter. Measurements at $1 \mathrm{kc}$./ $/ \mathrm{sec}$. show small effect at pressure of 2 bar.]

Brill, R., and others. 1957. Dielektrisches Verhalten von Eis-Ammoniumfluorid-Mischkristallen, von R. Brill, H. Ender und A. Feuersanger. Zeitschrift für Elektrochemie, Berichte der Bunsengesellschaft für physikalische Chemie, Bd. 6r, Nr. 8, p. 1071-75. [Mixed crystals exhibit a spectrum of relaxation times. The energy for dipole orientation is less than in pure ice.]

Gränicher, H., and others. I957. Dielectric relaxation and the electrical conductivity of ice crystals, by $\mathrm{H}$. Gränicher, C. Jaccard, P. Scherrer and A. Steinemann. Discussion of the Faraday Society, No. 23, p. 50-62. [Authoritative review: the jonic character of the d.c. conductivity is demonstrated. The dynamic behaviour is interpreted in terms of lattice imperfections.]

Siksna, R. 1957. Conduction of electricity through ice and snow. [Parts] I-II. Arkiv för Fysik, Bd. I I, Ht. 6, p. 495-528. [d.c. conductivity measurements for various field strengths, temperatures, orientations, and electrode surfaces.]

Steinemann, A., and Gränicher, H. 1957. Dielektrische Eigenschaften von Eiskristallen. I. Teil. - II. Teil. Helvetica Physica Acta, Vol. 30, Fasc. 7, p. 553-80 and (Steinemann) p. 581-6io. [Deviation from Debye spectrum at extremely low frequencies. Necessity for orientational defects.]

Ambach, W. 1958. Zur Bestimmung des Schmelzwassergehaltes des Schnees durch dielektrische Messungen. Zeitschrift für Gletscherkunde und Glazialgeologie, Bd. 4 , Ht. I-2, p. I-8. [Relation between the capacity of a standard capacitor containing snow and the water content of the snow.]

Lafargue, M., and Millecamps, R. G. 1958. Sur les propriétés électromagnétiques de la glace des glaciers. Comptes Rendus Hebdomadaires des Séances de l'Académie des Sciences (Paris), Tom. 247, No. 12, p. 884-86. [Field measurements from 50 to $400 \mathrm{kc} . / \mathrm{sec}$.]

Ockman, N. 1958. The infra-red and Raman spectra of ice. Advances in Physics, Vol. 7, No. 26, p. 199-220. [Authoritative review of all work published up to September 1957. Few measurements at frequencies less than $200 \mathrm{~cm} .^{-1}$. Many references.]

Ozawa, Y., and Kuroiwa, D. 1958. Dielectric properties of ice, snow, and supercooled water. Monograph Series of the Research Institute of Applied Electricity, Hokkaido University, No. 6, p. 31-37. [Application to problems of radio propagation and radar meteorology.]

Stanley, G. M. 1958. Studies of ground conductivity in the Territory of Alaska. University of Alaska. Geophysical Report Series, UAG-R8I. [Average values derived from radio propagation observations.] 
Gross, E. F. 1959. The vibration spectrum of the hydrogen bond. (In Hadži, D., ed. Hydrogen bonding; papers presented at the symposium on hydrogen bonding held at Ljubljana, 29. Fuly-3 August 1957. London, Pergamon Press, p. 203-09.) [Temperature dependence of low-frequency lines $\left(\sim 200 \mathrm{~cm}^{-1}\right)$ in the Raman spectrum of ice and solid $\mathrm{D}_{2} \mathrm{O}$. Reference to related work.]

Jaccard, C. r 959. Étude théorique et expérimentale des propriétés électriques de la glace. Helvetica Physica Acta, Vol. 32, Fasc. 2, p. 89-128. [Experimental work to discover which defects are important to d.c. conductivity, dielectric constant, and relaxation time. Experimental details.]

Kislovskiy, L. D. 1959. Opticheskiye kharakteristiki vody i l'da v infrakrasnoy i radiovolnovoy oblasti spektra. Optika i Spektroskopiya, Tom 7, Vyp. 3, p. 311-20 [Translation: Optical characteristics of water and ice in the infra-red and radiowave regions of the spectrum. Optics and Spectroscopy, Vol. 7, No. 3, p. 201-o6.] [Review. Infra-red data only for ice.]

Waite, A. H. 1959. Ice depth sounding with UHF radio in the Arctic and Antarctic. U.S. Army. Signals Research and Development Laboratory, Fort Monmouth, New Jersey, Technical Report No. 2092. [Contains measurements of permittivity at $30 \mathrm{Mc}$./sec. in holes $25 \mathrm{ft}$. $(7.5 \mathrm{~m}$.) deep in Antarctic ice shelf.]

Cook, J. C. I96o. RF electrical properties of salty ice and frozen earth. Fournal of Geophysical Research, Vol. 65 , No. 6, p. ${ }^{1} 767-7$ I. [Artificial samples measured at $100 \mathrm{Mc}$. $/ \mathrm{sec}$. down to $-40^{\circ} \mathrm{C}$. for salinities up to $3 \cdot 5$ per cent.]

Hatherton, T. 1960. Electrical resistivity of frozen earth. Fournal of Geophysical Research, Vol. 65, No. 9, p. 3023-24. [Various electrode spacings in the vicinity of Scott Base, Antarctica.]

Onsager, L., and Dupuis, M. I96o. The electrical properties of ice. (In Rendiconti della Scuola Internazionale di Fisica "Enrico Fermi". Corso 1o. Varenna, 15-27 Giugnio 1959. Bologna, Nicola Zanichelli, p. 294-315.) [Review, suggesting need for revision of ideas.]

Watt, A. D., and Maxwell, E. L. 1960. Measured electrical properties of snow and glacial ice. Fournal of Research of the National Bureau of Standards (Washington, D.C.), Sect. D, Vol. 64, No. 4, p. 357-63. [Field measurements using ELTRAN electrode arrays in the field at frequencies up to $200 \mathrm{kc}$. $/ \mathrm{sec}$.]

Wescott, E. M., and Hessler, V. P. I 960 . The effect of topography and geology on telluric currents. University of Alaska. Geophysical Report Series, UAG-R 107. [Includes ground resistivity measurements in Alaska using Wenner electrode system up to spacings of $90 \mathrm{ft}$. (27 m.).]

Brill, R., and Camp. P. R. I96r. Properties of ice. U.S. Cold Regions Research and Engineering Laboratory. Research Report 68. [Includes properties of mixed crystals, degree of perfection of glacier ice crystals and review of relaxation spectrum.]

Evans, S. 196r. Polar ionospheric spread echoes and radio frequency properties of ice shelves. Fournal of Geophysical Research, Vol. 66, No. 12, p. 4137-41. [Analysis of ionograms shows that 1 to 10 Mc./sec. radiation penetrates ice shelves.]

Hasted, J. B. 196r. The dielectric properties of water. Progress in Dielectrics, Vol. 3, p. Ior-49. [Contains a discussion of the lattice structure and imperfections in ice.]

Yoshino, T. I961. Radio wave propagation on the ice cap. Antarctic Record (Tokyo), No. I I, p. 228-33. [Measurements in tuned circuits and transmission lines from 1.5 to $3,000 \mathrm{Mc}$./sec. using snow samples in Antarctica.]

Kopp, M. 1962. Conductivité électrique de la neige, au courant continu. Zeitschrift für angewandte Mathematik und Physik, Bd. I 3 , Ht. 5, p. $43 \mathrm{I}-4 \mathrm{I}$. [Wide range of samples, temperatures $0^{\circ}$ to $-5^{\circ} \mathrm{C}$.]

Kuroiwa, D. I962. Electrical properties of snow. (In Bader, H. The physics and mechanics of snow as a material. U.S. Cold Regions Research and Engineering Laboratory. Cold regions science and engineering. Hanover, N.H., Pt. II, Sect. B, p. 63-79.) [Collected results and new measurements of the effect of thick ice on U.H.F. antennae.]

Onsager, L., and Dupuis, M. 1962. The electrical properties of ice. (In Pesce, B., ed. Electrolytes: proceedings of an international symposium held in Trieste, June 1959. Oxford, Pergamon Press, p. 27-46.) [Authoritative review of conductivity, relaxation, and temperature coefficients in terms of Bjerrum defects.]

Waite, A. H., and Schmidt, S. J. ${ }^{1962 . ~ G r o s s ~ e r r o r s ~ i n ~ h e i g h t ~ i n d i c a t i o n ~ f r o m ~ p u l s e d ~ r a d a r ~ a l t i m e t e r s ~ o p e r a t i n g ~}$ over thick ice or snow. Proceedings of the Institute of Radio Engineers, Vol. 50, No. 6, p. 1515-20. [Greenland and Antarctica with radar altimeter on snow surface.]

Dunitz, J. D. 1963. Nature of orientational defects in ice. Nature, Vol. 197, No. 487o, p. 86o-62. [Approximate quantitative explanation of low-frequency conductivity.]

Gränicher, H. ${ }_{9} 6_{3}$. Properties and lattice imperfections of ice crystals and the behaviour of $\mathrm{H}_{2} \mathrm{O}-\mathrm{HF}_{\mathrm{F}}$ solid solutions. Physik der kondensierten Materie, Bd. I, Ht. I, p. 1-12. [Review containing summarized numerical data.]

Heinmets, F., and Blum, R. I963. Conductivity measurements on pure ice. Transactions of the Faraday Society, Vol. 59 , Pt. 5, p. $11^{1}{ }^{1-46}$. [Direct current. Activation energy $24 \cdot 2 \mathrm{kcal}$. Conductivity $\mathrm{I} \cdot 6 \times \mathrm{IO}^{-7} \mathrm{mho} / \mathrm{m}$. at $\left.-10^{\circ} \mathrm{C}.\right]$

Addison, J. R., and Pounder, E. R. 1964. Electrical properties of saline ice. Ice Research Project, McGill University. Final report, project 8623 , task $86230 \mathrm{I}$. [Artificially frozen sea-water of various salinities at $-22^{\circ} \mathrm{C}$. Dielectric constant and resistivity measured from $20 \mathrm{c}$./sec. to $100 \mathrm{Mc} . / \mathrm{sec}$.

Eigen, M., and others. 1964. Über das kinetische Verhalten von Protonen und Deuteronen in Eiskristallen, von M. Eigen, L. de Maeyer und H.-C. Spatz. Berichte der Bunsengesellschaft für physikalische Chemie, Bd. 68, Nr. I, p. 19-29. [Contains lowest measured value of d.c. conductivity. Also temperature coefficient.]

Nottarp, K. 1964. Dielectric measurements on Antarctic snow at 3,0oo Mc./sec. Fournal of Glaciology, Vol. 5, No. 37, p. 1 34 . [Letter. Brief announcement of propagation between pits using tellurometer.]

Ragle, R. H., and others. I964. Ice core studies of Ward Hunt Ice Shelf, 1960, by R. H. Ragle, R. G. Blair and L. E. Persson. Fournal of Glaciology, Vol. 5, No. 37, p. 39-59. [Contains table of measurements by Westphal from ioo to $\mathrm{I}, \mathrm{ooo} \mathrm{Mc} . / \mathrm{sec}$. on core samples.] 


\section{APPENDIX B \\ Dispersion Effects due to Relaxation and Resonance}

In liquids and solids containing polar molecules the orientation of the molecules in an applied electric field will be the dominating factor contributing to the total polarizability at the lowest frequencies, usually extending into the radio or millimetre wavelength range. Molecules which are unpolarized in the absence of an applied electric field produce dispersion effects by molecular vibration and rotation in the near and far infra-red respectively.

\section{Relaxation spectra}

If the orientation of a molecular dipole with respect to an applied electric field is described by an over-critically damped oscillation of relaxation time $\tau$ then the relative permittivity at an angular frequency $\omega$ is given by Debye's formula

$$
\epsilon=\epsilon_{\infty}+\frac{\epsilon_{s}-\epsilon_{\infty}}{\mathrm{I}+j \omega \tau}
$$

suffix $s$ refers to static values, that is values at frequencies very much less than $\mathrm{I} / \tau$. Suffix $\infty$ refers to values at frequencies very much greater than $\mathrm{I} / \tau$. The ordered orientation is resisted by thermal agitation so that the polarizability may be simply related to absolute temperature by the Boltzmann principle. We find

$$
\tau=A \exp (E / R T)
$$

and the constants $A$ and $E$ are characteristic of the molecule. In this type of spectrum the imaginary part of $\epsilon, \epsilon^{\prime \prime}$, reaches a maximum at a frequency $\mathrm{I} / 2 \pi \tau$ and the real part, $\epsilon^{\prime}$, decreases monotonically with increasing frequency through a range of about one decade in the vicinity of $\mathrm{I} / 2 \pi \tau$. In practical work it may be more convenient to use the loss tangent, which reaches a maximum at a frequency $f_{m}=\sqrt{ }\left(\epsilon_{s} / \epsilon_{\infty}\right) / 2 \pi \tau$ cycles per second.

Cole and Cole (194I) pointed out that if we plot $\epsilon^{\prime \prime}$ versus $\epsilon^{\prime}$, points obeying the Debye equation lie on a semicircle, as in Figure $\mathrm{I}$, by which this type of spectrum may be recognized in practice. Material with a continuous range of relaxation times spread around a mean value have a Cole-Cole diagram which is broader and flatter, and materials with widely separated relaxation times may be recognized by their separate contributions.

\section{Resonant absorption}

Atomic spectra and molecular resonance phenomena such as vibration and rotation, on the other hand, are characterized by so-called anomalous dispersion. The relative permittivity and refractive index rise with frequency and then decrease abruptly in the vicinity of the resonant frequency, $\omega_{r}$, where the loss factor is a maximum as shown in Figure io.

$$
\epsilon(\omega)=\epsilon \text { (high frequency) }+\frac{C}{\omega_{r}^{2}-\omega^{2}-2 j \omega \alpha} .
$$

The quantity $C$ defines the strength of the absorption and $2 \alpha$ is the width of the spectrum of $\epsilon$ " between half-maximum values.

For both these types of spectrum, by using approximations in the above expressions, we can show that at frequencies far removed from the absorption bands the value of $\epsilon^{\prime}$ is constant. At very low frequencies $\epsilon "$ is small and proportional to frequency. For relaxation spectra, at 
frequencies higher than the absorption band, $\epsilon "$ is inversely proportional to frequency (thus $f \tan \delta$ is constant). For resonance spectra, on the skirts of the absorption band $\epsilon^{\prime \prime}$ is inversely proportional to the deviation from resonance. We refer to these facts in section 2.
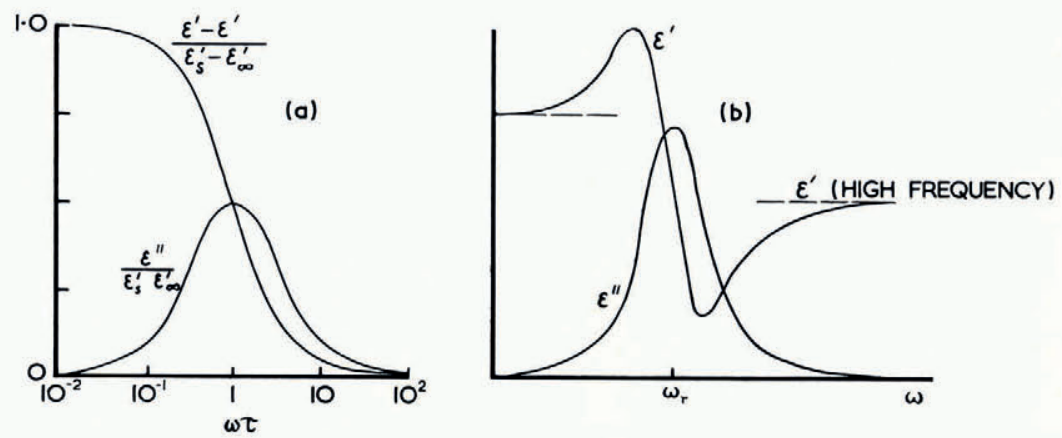

Fig. 10. (a) Relaxation spectrum with normalized ordinates. The relaxation time is $\tau$ and $\omega$ is the angular frequency.

(b) Resonance spectrum or anomalous absorption. The scale of ordinates is arbitrary; the resonant frequency is $\omega_{r}$

\section{APPENDIX C}

Macroscopic Dielegtric Parameters and Electromagnetic Waves

\section{Complex permittivity}

According to the interests of the observer, various sets of parameters have been introduced to describe the properties of dielectric materials, from their behaviour in static electric and magnetic fields through increasing frequencies up to the X-ray range. In this paper we deal with the complex relative permittivity

$$
\epsilon=\epsilon^{\prime}-j \epsilon^{\prime \prime}
$$

where $\epsilon^{\prime}$ is the relative permittivity (or dielectric constant) based on vacuum as unity, and $\epsilon^{\prime \prime}$ is the relative loss factor. The dimensionless ratio $\epsilon^{\prime \prime} / \epsilon^{\prime}$ is equal to $\tan \delta$ or loss tangent, where $\delta$ is the phase angle between the displacement current and the total current in an alternating electric field. The term "power factor" frequently used in engineering, is strictly $\sin \delta$ which is the ratio of the conduction current to the total current, but in low-loss media the power factor is small and may be taken equal to $\tan \delta$.

We use the rational M.K.S. system of units; $\epsilon_{0}$ and $\mu_{0}$ are the electric permittivity and magnetic permeability of vacuum and we assume we are dealing with non-magnetic materials.

\section{Conductivity}

Some authors refer to the conductivity in mhos per metre, $\sigma$, derived from measurements of the apparent parallel leakage resistance of a capacitor containing the dielectric under test. Apart from this consideration $\sigma$ does not lend itself to physical interpretation; it is not in general equal to the ohmic conductivity measured by direct currents because additional power loss is incurred in each reversal of polarization of the material with the electric field. The apparent conductivity is related to the dissipation by

$$
\sigma=\omega \epsilon_{\mathrm{o}} \epsilon^{\prime \prime}
$$


where $\omega$ is the angular frequency in radians per second. Conversely, if the direct-current conductivity is known, its contribution to the total dissipation may be found by substitution in this formula.

\section{Velocity}

The phase velocity, $v$, of an electromagnetic wave is given by

$$
\mathrm{I} / v^{2}=\frac{1}{2} \mu_{0} \epsilon_{0} \epsilon^{\prime}\left(\sqrt{ }\left(\mathrm{I}+\tan ^{2} \delta\right)+\mathrm{I}\right)
$$

when $\tan \delta<0 \cdot \mathrm{I}$,

$$
v=c / \sqrt{ } \epsilon^{\prime}
$$

where $c=2 \cdot 998 \times 10^{8} \mathrm{~m}$. $/ \mathrm{sec}$, the velocity of electromagnetic waves in vacuum. If $\tan \delta=0 \cdot \mathrm{I}$ this approximation for $v$ is in error by $+\mathrm{I}$ part in $\mathrm{I}$,ooo. Thus the index of refraction used in optics, $n$, may be taken equal to $\sqrt{ } \epsilon^{\prime}$ when $\tan \delta \leqslant 0 \cdot \mathrm{I}$.

\section{Attenuation}

The field strength of an electromagnetic wave decreases with distance with exponent $\alpha$ where

$$
\begin{aligned}
(\alpha / \omega)^{2} & ={ }_{2}^{1} \mu_{0} \epsilon_{0} \epsilon^{\prime}\left[\sqrt{ }\left(\mathrm{I}+\tan ^{2} \delta\right)-\mathrm{I}\right] ; \\
\alpha & \sim\left(\omega \sqrt{ } \epsilon^{\prime} / 2 c\right) \tan \delta .
\end{aligned}
$$

when $\tan \delta<0 \cdot \mathrm{I}$,

In more convenient practical terms the power decreases by $9 \cdot 10 \times 10^{-2} \sqrt{ } \epsilon^{\prime} f \tan \delta \mathrm{dB} . / \mathrm{m}$. where $f$ is the frequency in Mc./sec.

The index of absorption used in optics measures the attenuation per radian, $\kappa=\alpha v / \omega$; with the above approximation for $\alpha, \kappa=\frac{1}{2} \tan \delta$.

\section{Impedance}

The intrinsic impedance of the medium, $\eta$, which is the ratio of the electric and magnetic field strengths in an electromagnetic wave reduces to

$$
\eta=\left(\mu_{0} / \epsilon_{0} \epsilon^{\prime}\right)^{\frac{1}{2}}\left(\mathrm{I}+\frac{1}{2} j \tan \delta\right)
$$

when $\tan \delta<0 \cdot 1$, or $377 / \sqrt{ } \epsilon^{\prime}$ ohms when the small phase difference is of no interest.

\section{Quality}

The "quality factor" of the dielectric, $Q=\mathrm{r} / \tan \delta$. This term is more often used to describe the dissipation of a complete tuned circuit and the majority of the loss usually occurs in the inductance (in resistance of the conductors, eddy currents in the core, and hysterisis loss in the core) and not in the dielectric used in the capacitor.

In general,

$$
Q=\frac{\mathrm{I}}{2 \pi}\left[\frac{\text { average energy stored in the circuit }}{\text { average energy dissipated per cycle }}\right]
$$

and

$$
\mathrm{I} / Q=\mathrm{I} / Q_{\mathrm{r}}+\mathrm{I} / Q_{2}+\ldots
$$

where $Q_{1}, Q_{2}$, etc., are the quality factors of the individual components. This accounts for the difficulty of measuring $\tan \delta$ in a low-loss material such as ice by inserting it between the plates of a capacitor used in a tuned circuit where the total $Q$ is likely to be dominated by the losses in the inductance. 